\title{
Drug adherence behavior among hypertensive out-patients at a tertiary health institution in Manicaland province, Zimbabwe, 20I I
}

This article was published in the following Dove Press journal:

Patient Preference and Adherence

16 January 2013

Number of times this article has been viewed

\author{
Fadzai NN Mukora- \\ Mutseyekwa \\ Elizabeth M Chadambuka \\ Faculty of Health Sciences, Africa \\ University, Mutare, Zimbabwe
}

Correspondence: Fadzai NN MukoraMutseyekwa

Africa University, Box 1320, Mutare,

Zimbabwe

Tel +2632065269

Email mutseyekwaf@africau.edu
Objectives: This study investigated the level of drug adherence among hypertensive outpatients at a tertiary hospital in Zimbabwe. Specific objectives included measurement of blood pressure (BP) control achievement, estimating prevalence of drug adherence behavior, and establishing the association between drug adherence behavior and achievement of BP control.

Methods and materials: An analytic cross sectional design was applied on a convenience sample of 102 participants using an interviewer administered questionnaire. Self-reported adherence was assessed using the Morisky Medication Adherence Scale.

Findings: The median age of participants was 68.5 years $\left(\mathrm{Q}_{1} 61 ; \mathrm{Q}_{3} 76\right)$. The majority were female $(\mathrm{n}=71 ; 69.6 \%)$. BP control $(<140 / 90 \mathrm{mmHg})$ was achieved in $52 \%(\mathrm{n}=53)$. Self-reported drug adherence was $40.2 \%(n=42)$. After multivariate logistic regression analysis, participants with normal BP measurements were more than three times as likely to report maximal adherence to prescribed drug schedules (odds ratio 3.37; 95\% confidence interval: 1.38-8.24).

Conclusion: Poor drug adherence behavior prevails among hypertensive outpatients. This contributes to poor achievement of BP control. The hospital is recommended to set up a specialized hypertension clinic in the Out-patients' Department where an intensified health education package can be introduced as well as community awareness programs on the importance of medication adherence.

Keywords: drug adherence, behavior, hypertension

\section{Background}

Sub Saharan Africa and most of the other low to middle income countries (LMICs) are currently experiencing a "dual burden of disease" with the impact of non-communicable diseases (NCDs) increasingly exerting added pressure to the health systems that are already struggling to cope with infectious diseases. ${ }^{1}$ According to a World Health Organization (WHO) report in 2005, 28 million people in LMICs died from an NCD and $80 \%$ of mortality due to NCDs occurred in LMICs. ${ }^{2}$ The WHO report further stated that in these same states, five times more people died from cardiovascular diseases than from HIV.

The Zimbabwe NCDs surveillance report revealed a high prevalence of hypertension in Zimbabwe. A significant proportion of the population was "undiagnosed," meaning that the condition was only picked up at screening for the purposes of the survey. In the 25-34 year age group, a history of hypertension was given in $7.9 \%$ of respondents. This percentage rose to $30.9 \%$ in the above 65 years age group. ${ }^{3}$ submit your manuscript | www.dovepress.com

http://dx.doi.org/1 0.21 47/PPA.S40295 
Studies and program statistics from very different settings all over the world show that less than satisfactory levels of blood pressure (BP) control are achieved in most hypertensive patients to whom medications have been prescribed. A MEDLINE database search revealed that achievement of $\mathrm{BP}$ control in hypertensive patients on treatment varies from $5.4 \%$ in Korea to $58 \%$ in Barbados. ${ }^{4}$

The success of strategies for BP management is ultimately dependent on the ability and willingness of the patient to change and maintain certain behaviors. ${ }^{5}$ Non-adherence to prescribed treatment interventions is a public health problem for which prevention is an important goal.

Treatment adherence is the degree of compliance with prescribed therapeutic measures, which can be medicinal or not, aiming at maintaining BP levels. ${ }^{6}$ The term "adherence" is comprehensive and should reflect both taking the medicine as directed (compliance) and continuing to take the medication for the duration required (persistence). ${ }^{7}$

Many patients reduce their own dosage to below the therapeutic range. ${ }^{8}$ It has been estimated that within the first year of treatment $16 \%-50 \%$ of hypertensive patients discontinue their anti-hypertensive medications and missed medication doses are common even among patients remaining on long-term treatment. ${ }^{9}$ As many as $65 \%$ of patients voluntarily stop taking their prescribed medications. ${ }^{8-10}$

\section{Study site}

The study setting was Mutare Provincial Hospital (MPH) in Manicaland province. The catchment area for MPH covers the entire population of Manicaland province (estimated at about 1.7 million) and it serves as the province's tertiary referral center.

In practice, patients with hypertensive disease are reviewed monthly in the nurse clinic in the General Outpatients' Department (GOPD) at MPH if their condition is stable. An average of 414 follow-up and 32 new consultations for hypertensive disease were made every month in the year 2010 .

Unpublished reports from the MPH Out-Patients' Department (OPD) in 2010/2011 indicated a high prevalence of patients ( $48 \%$ of the 414 registered hypertension cases) requiring referral for further management at the next level of care during the course of the previous year (MPH OPD records, 2010-2011). It was postulated that the observed high prevalence of uncontrolled BPs in hypertensive patients on treatment could be explained by a low uptake of drug adherence behavior.

\section{Methods}

An analytic cross-sectional survey was conducted in order to meet the specific objectives which included measurement of BP control achievement, estimation of prevalence of drug adherence behavior, and establishing the association between achievement of BP control and drug adherence behavior within the particular context. The study population comprised adult patients with a diagnosis of hypertension reviewed at the GOPD at MPH, where just over 400 follow up cases of hypertension are reviewed every month.

A structured, interviewer-administered questionnaire was used to collect data. Measurement of BP was based on the 7th Joint National Committee on Prevention, Detection, Evaluation, and Treatment of High Blood Pressure (JCN 7) Classification. ${ }^{11} \mathrm{BP}$ was measured on clients at rest on two occasions at least 30 minutes apart by two different individuals using a manual sphygmomanometer. The average of these two readings was calculated and entered as the current BP reading for the purpose of this analysis.

In order to assess achievement of BP control, systolic and diastolic BP measurements were noted for the current visit as well as for the preceding review visit. Information supplied by participants was cross checked with entries in their OPD review cards.

Self-reported adherence behavior was assessed via the use of a standard international adherence measure known as the Morisky Medication Adherence Scale (MMAS-4; alpha reliability $=0.61$, which was incorporated in the data collection instrument. The MMAS is a 4-item self-report scale with original binary response options (yes/no). This scale has demonstrated both concurrent and predictive validity with regard to $\mathrm{BP}$ control at 2 years and 5 years, respectively $(P<0.01) .{ }^{12}$ The classification of the patients as adherent, or as non-adherent, depended on the proportion of binary answers. Patients who responded "No" to three or more of the four MMAS items (MMAS score of 0 or 1 ) were classified as adherent. Patients responding "No" to fewer than three of the four items (MMAS score 2, 3, or 4) were classified as non-adherent.

Data were entered and analyzed using the Epi Info 3.5.1 computer software package (Centers for Disease Control and Prevention, Atlanta, GA, USA). Descriptive analysis was conducted using frequencies. Pearson's Chi-square tests were used to measure significant relationships. Comparisons for which $P$-values were below 0.05 were considered statistically significant. 


\section{Results}

During the 4-week period of data collection, 102 participants were recruited and interviewed using an interviewer-based questionnaire.

\section{Achievement of BP control}

In the sample of 102 subjects on prescribed drug treatment for hypertension, BP control, based on the JCN 7 classification, was achieved in $52 \%$ of the patients $(n=53)$. Figure 1 illustrates the distribution of measurements obtained from the patients on the dates of presentation.

Participants measured systolic BP (SBP) of $147.24 \pm 24.35 \mathrm{mmHg}$ [mean \pm standard deviation (SD)] with a median SBP of $139\left(Q_{1} 130 ; Q_{3} 164\right)$. Average diastolic BP (DBP) measurement was $89.04 \pm 13.46 \mathrm{mmHg}(\mathrm{Mean} \pm \mathrm{SD})$, with a median DBP of $87\left(\mathrm{Q}_{1} 81 ; \mathrm{Q}_{3} 100\right)$.

BP control on the previous date of consultation was obtained by checking on the patients' OPD cards. Achievement of BP control on the day of the previous consultation was noted to have been even lower at $43.9 \%$.

BP control was comparable between the sexes. In females $(\mathrm{n}=71)$, BP control was present in $50.7 \%(\mathrm{n}=36)$, while in males $(n=31)$, it was achieved in $54.8 \%(n=17)$. There was no difference between the two proportions at the $95 \%$ significance level.

The different age categories appeared to show dissimilar proportions of BP control achievement. BP control was achieved in $76.9 \%$ of participants aged above 80 years old (10/13); $65.6 \%$ of participants aged 71-80 (21/32); $44.1 \%$ of participants aged $61-70(15 / 34) ; 50.0 \%$ of participants aged $51-60(4 / 8)$; and $20 \%$ of participants aged below $50(3 / 15)$. However, Chi-square determination of difference in achievement of BP control was not valid (an expected frequency $<5$ ).

Linear regression analysis of the relationship between age and DBP measurement and age and SBP showed a statistically significant relationship with a single unit change

Table I Classification of hypertension according to the 7th Joint National Committee on Prevention, Detection, Evaluation, and Treatment of High Blood Pressure (JNC 7)

\begin{tabular}{lccc}
\hline Category & SBP $\mathbf{~ m m H g}$ & & DBP $\mathbf{~ m ~ H ~ H g}$ \\
\hline Classification of blood pressure (BP) & & \\
Normal & $<120$ & and & $<80$ \\
Prehypertension & $120-139$ & or & $80-89$ \\
Hypertension, Stage I & $140-159$ & or & $90-99$ \\
Hypertension, Stage 2 & $\geq 160$ & or & $\geq 100$ \\
\hline
\end{tabular}

Abbreviations: SBP, systolic blood pressure; DBP, diastolic blood pressure.

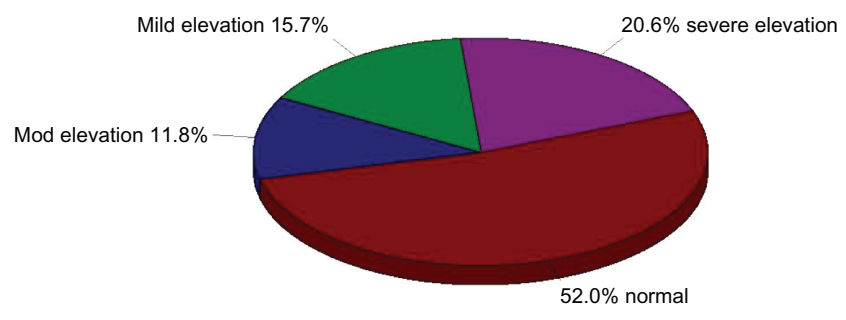

Figure I BP measurement recorded on the date of data collection. Abbreviation: mod, moderate.

in age resulting in a lowering of the DBP and SBP measurements by a factor of 0.4 and 0.7 , respectively, and age being responsible for $16 \%$ of the variation in DBP and $11 \%$ of the variation in SBP (95\% confidence).

\section{The prevalence of drug adherence behaviors}

Only $40.2 \%$ of the participants reported that they took their medications as prescribed at all times $(n=41)$. The other $59.8 \%(n=61)$ scored $\geq 2$ points on the MMAS, signaling that they were not consistently adherent. The distribution of the extent of this non-adherence is presented in Figure 2.

\section{Association between adherence to prescribed schedules for drug/medication administration and achievement of BP control}

Patients who reported adherence to medication measured DBP of $83 \pm 10.83 \mathrm{mmHg}$ (mean \pm SD) and non-adherent participants had DBP of $93.01 \pm 13.60 \mathrm{mmHg}$ (mean \pm SD).

For SBP, adherent participants measured $136.17 \pm 21.74 \mathrm{mmHg}$ (mean $\pm \mathrm{SD}$ ) and non-adherent participants measured $154.67 \pm 23.31 \mathrm{mmHg}$ (mean $\pm \mathrm{SD})$.

\section{Drug adherence MAS score}

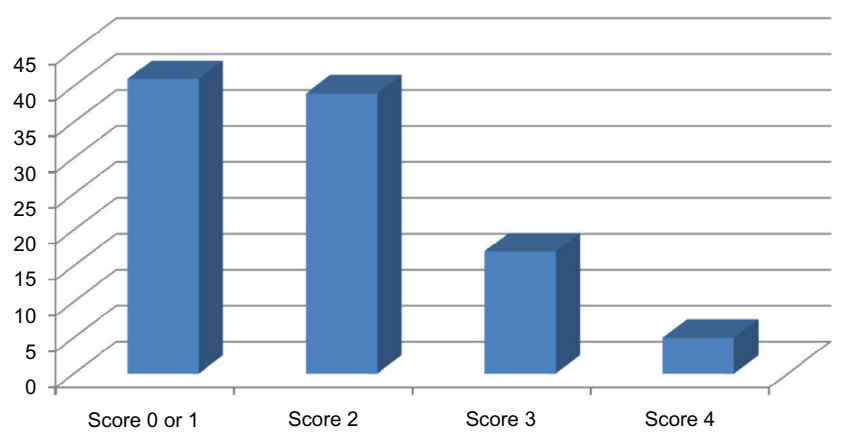

Figure 2 Self-reported adherence to prescribed drug administration schedules. Abbreviation: MAS, Medication Adherence Scale. 
Therefore, compared with their non-adherent counterparts, adherent patients exhibited lower mean SBP $(-18.5 \mathrm{mmHg})$ and lower mean DBP $(-10.01 \mathrm{mmHg})(P<0.05)$.

As seen in Table 2, participants with normal BP measurements were almost four times more likely to report maximal adherence to prescribed drug administration schedules than their non-adherent counterparts (odds ratio $=3.73 ; 95 \%$ confidence interval: $1.60-8.69 ; P=0.002$ ).

Multivariate logistic regression analysis considering the impact of age (older than 65), gender, body mass index, and drug adherence on achievement of BP control yielded only drug adherence as exhibiting a statistically significant association with the desired outcome (odds ratio $=3.37 ; 95 \%$ confidence interval: $1.38-8.24 ; P=0.008)$.

\section{Discussion}

\section{Achievement of BP control}

Uncontrolled BP is defined by the American Society of Hypertension as SBP of $140 \mathrm{mmHg}$ and above and/or DBP of $90 \mathrm{mmHg}$ and above. ${ }^{13}$ Based on this definition, BP control was achieved in $52 \%$ of the participants. This is far less than desired considering that the whole point of prescribing treatments and reviewing patients regularly is to achieve control of the condition. However, this result is well in keeping with global trends ranging from $5.4 \%$ to $58 \% .{ }^{4}$ It is even higher than rates observed in better resourced treatment programmes. ${ }^{14,15}$

Achievement of BP control is essential in order to avert the occurrence of adverse outcomes such as physical complications and death. With as much as $20.6 \%$ of patients in this study exhibiting severe levels of BP elevation ( $\geq 180 / 110)$, the likelihood of adverse outcomes is very high. In this regard, it is essential that causes of failure of hypertension management be identified and rectified at both the institutional as well as at the community level. Because the difference in achievement of control between the sexes was not statistically significant, measures should be equally targeted at both male and female hypertensive patients. The apparent improvement in achievement of BP control with older age may point towards the need for targeted/age-specified interventions. There may also be a need for equitable allocation of interventions with younger patients requiring more effort than their older counterparts. Further investigation is necessary to reveal the factors that contribute to poorer adherence in younger people in this particular context. Studies on medication adherence in other contexts have also yielded similar findings with regard to the impact of age. ${ }^{16,17}$

\section{The prevalence of drug adherence behaviors}

Self-reported consistent drug adherence behavior among this population was unacceptably low at around $40 \%$ of hypertensive cases on prescribed medications. This prevalence rate was comparable to that observed in the Colorado inner city health system (36.3\%). The inner city rate was almost half of the adherence level observed in the more prosperous health maintenance organization population from the same state $(72.1 \%){ }^{18}$

The low drug adherence prevalence obtained shows the urgent need for interventions within the hypertensive population accessing services at MPH. It is important to gain a clearer understanding of the factors contributing to this non-adherence phenomenon. Authorities have expressed mixed opinions over the use of self-reported measurements of adherence. However, literature review has shown that these kinds of measurements, when applied correctly, will provide

Table 2 Distribution of relevant characteristics between adherent and non-adherent participants

\begin{tabular}{|c|c|c|c|c|c|}
\hline Characteristic & Adherers, $n=4 I(40.2 \%)$ & Non adherers, $\mathrm{n}=6 \mathrm{I}(59.8 \%)$ & Odds ratio & $(95 \% \mathrm{Cl})$ & $P$-value \\
\hline \multicolumn{6}{|l|}{ BP control current } \\
\hline Control achieved* & $29(70.7)$ & $24(39.3)$ & 3.73 & $1.60-8.69$ & 0.002 \\
\hline Uncontrolled BP & $12(29.3)$ & $37(60.7)$ & & & \\
\hline \multicolumn{6}{|l|}{ Sex } \\
\hline Female & $24(58.5)$ & $47(77.0)$ & 0.42 & $0.16-1.09$ & 0.04 \\
\hline Male & $17(4 \mid .5)$ & $14(23.0)$ & & & \\
\hline \multicolumn{6}{|l|}{ BMI } \\
\hline Overweight/obese $\mathrm{e}^{\ddagger}$ & $13(31.7)$ & $31(50.8)$ & 0.45 & $0.18-1.10$ & 0.04 \\
\hline Normal/underweight ${ }^{\ddagger}$ & $28(68.3)$ & $30(49.2)$ & & & \\
\hline \multicolumn{6}{|l|}{ Age } \\
\hline Less than 65 & $9(22.0)$ & $27(44.3)$ & 2.82 & $1.07-7.84$ & 0.02 \\
\hline 65 and above & $32(78.0)$ & $34(55.7)$ & & & \\
\hline
\end{tabular}

Notes: *Achievement of BP control defined as achieving an SBP $<140 \mathrm{mmHg}$ and/or a DBP $<90 \mathrm{mmHg}$ (normal and pre-hypertension BP); $<$ 18.5; normal 18.5-24.9; overweight 25.0-29.9; obese > 30 (CDC).

Abbreviations: BP, blood pressure; Cl, confidence interval; BMI, body mass index; SBP, systolic blood pressure; DBP, diastolic blood pressure; CDC, Centers for Disease Control and Prevention. 
results that are complimentary to refill-based measurements which have long been considered more reliable. ${ }^{19}$ The assessment tool for self-reported adherence that was adopted for this study actually demonstrated both concurrent and predictive validity in past research. ${ }^{12}$

Argument against the reliability of these results would only imply that prevalence rates of drug adherence behaviors are actually worse than reported. The hypothesis is that non-adherence is known by the patients themselves to be a negative behavior for which they can be reprimanded and so faced with enquiry in an interview setting, non-adherent participants may be inclined to respond untruthfully and claim that they are compliant to drug taking instructions. In the event that actual drug adherence levels at MPH are even lower than $40.2 \%$, then the need for urgent intervention becomes even more pronounced.

\section{Association between adherence to prescribed schedules for drug/medication administration and achievement of BP control}

A statistically significant association was established between achievement of BP control and self-reported drug adherence (odds ratio $=3.73 ; P<0.05$ ). These findings are in concurrence with a number of other studies carried out all over the world. ${ }^{12,19,20}$

While it will sound logical that failure to adhere to prescribed medications would be a direct cause of failure to achieve BP control, experts argue that issues involved in BP control are of a highly complex nature and cannot be broken down as simplistically as that. A systematic review done in 2004 that covered 25 studies revealed that there was not enough convincing empirical evidence to support the hypothesis that poor drug adherence accounted for the inadequate control of BP in most patients. ${ }^{21}$

\section{Conclusion}

Achievement of BP control was suboptimal in the sample population at MPH OPD at only 52\%. Drug adherence within this population was also very low with less than half of participants reporting that they were adherent to their medication (40.2\%). This low level of drug adherence was found to be related to the poor BP control observed. Participants with normal BP measurements were almost four times more likely to report maximal adherence to prescribed drug administration schedules than their non-adherent counterparts. The hospital is recommended to set up a specialized hypertension clinic in OPD where an intensified health education package can be introduced as well as community awareness programs on the importance of medication adherence.

\section{Study limitations}

The size of the sample was limited by the size of the operation of the clinic, hence, affecting the study power. The BP recorded at the initial time of drug prescription was only available in the form of patient handheld cards from previous consultations. Such a baseline measurement is difficult to consider for the purposes of making conclusions in research because of the lack of standardization in the data collection process.

\section{Acknowledgments}

We are greatly indebted to the Manicaland Provincial Medical Directorate office and the clinical team from the MPH OPD for their exceptional support and cooperation.

\section{Disclosure}

The authors report no conflicts of interest in this work.

\section{References}

1. World Health Organization. Cardiovascular Disease in the African Region: Current Situation and Perspectives. Geneva: World Health Organization; 2005. Available from: http://apps.who.int/iris/ bitstream/10665/1871/1/AFR\%20RC55-12.pdf. Accessed December 7, 2012.

2. World Health Organization. Preventing Chronic Diseases: A Vital Investment. Geneva: World Health Organisation; 2005. Available from: http://www.who.int/chp/chronic_disease_report/full_report.pdf. Accessed December 7, 2012.

3. World Health Organization. National Survey: Zimbabwe Non-Communicable Disease Risk Factors - (ZiNCoDs), Preliminary Report. Geneva: World Health Organization; 2005. Available from: http://www.who.int/chp/steps/STEPS_Zimbabwe_Data.pdf. Accessed December 7, 2012.

4. Kearney P, Whelton M, Reynolds K, Whelton PK, He J. Worldwide prevalence of hypertension: a systematic review. J Hypertens. 2004; 22(1):11-19.

5. NKF K/DOQI GUIDELINES [webpage on the Internet]. New York: National Kidney Foundation; 2012. Available from: http://www kidney.org/professionals/kdoqi/guidelines_bp/guide_5.htm. Accessed March 29, 2011.

6. Pierin AMG. Nursing and research in arterial hypertension. Acta Paul Enferm. 2010;23(5):7-8.

7. National Council on Patient Information and Education. Enhancing Prescription Medicine Adherence: A National Action Plan. Rockville: National Council on Patient Information and Education; 2007. Available from: http://www.talkaboutrx.org/documents/enhancing_prescription_ medicine_adherence.pdf. Accessed December 7, 2012.

8. Degli Esposti E, Sturani A, Degli Esposti L, et al. Pharmacoutilization of antihypertensive drugs: A model of analysis. Int J Clin Pharmacol Ther. 2001;39(6):251-258.

9. Flack JM, Novikov SV, Ferrario CM. Benefits of adherence to antihypertensive drug therapy. Eur Heart J. 1996;17 Suppl A:16-20.

10. Cheng JW, Kalis MM, Feifer S. Patient-reported adherence to guidelines of the Sixth Joint National Committee on Prevention, Detection, Evaluation, and Treatment of High Blood Pressure. Pharmacotherapy. 2001;21(7):828-841. 
11. US Department of Health and Human Services. Reference Card from the Seventh Report of the Joint National Committee on Prevention, Detection, Evaluation, and Treatment of High Blood Pressure (JNC 7). Bethesda: US Department of Health and Human Services; 2003. Available from: http://www.nhlbi.nih.gov/guidelines/hypertension/ phycard.pdf. Accessed December 7, 2012.

12. Morisky DE, Green LW, Levine DM. Concurrent and predictive validity of a self-reported measure of medication adherence. Med Care. 1986; 24(1):67-74.

13. Goldfarb B. ASH Panel proposes new hypertension definition. DOC NEWS. 2005;2(7):1-7.

14. Hajjar I, Kotchen TA. Trends in prevalence, awareness, treatment, and control of hypertension in the United States, 1988-2000. JAMA. 2003;290(2):199-206.

15. Dennison CR, Peer N, Steyn K, Levitt NS, Hill MN. Determinants of hypertension care and control among peri-urban Black South Africans: the HiHi study. Ethn Dis. 2007;17(3):484-491.

16. Hinkin CH, Hardy DJ, Mason KI, et al. Medication adherence in HIV infected adults: effect of patient age, cognitive status and substance abuse. AIDS. 2004;18 Supp1 1:S19-S25.
17. Cohen MJ, Shaykevich S, Cawthon C, Kripalani S, Paasche-Orlow MK, Schnipper JL. Predictors of medication adherence post discharge: the impact of patient age, insurance status, and prior adherence. $J$ Hosp Med. 2012;7(6):470-475.

18. Steiner JF, Ho PM, Beaty BL, et al. Sociodemographic ande linical characteristics are not clinically useful predictors of refill adherence in patients with hypertension. Circulation: Cardiovascular Quality and Outcomes. 2009;2:451-457.

19. Morris AB, Li J, Kroenke K, Bruner-England TE, Young JM, Murray MD. Factors associated with drug adherence and blood pressure control in patients with hypertension. Pharmacotherapy. 2006;26(4): 483-492.

20. Nelson MR, Reid CM, Ryan P, Willson K, Yelland L. Self-reported adherence with medication and cardiovascular disease outcomes in the Second Australian National Blood Pressure Study (ANBP2). Med J Aust. 2006;185(9):487-489.

21. Wetzels GE, Nelemans P, Schouten JS, Prins MH. Facts and fiction of poor compliance as a cause of inadequate blood pressure control: a systematic review. J Hypertens. 2004;22(10):1849-1855.
Patient Preference and Adherence

\section{Publish your work in this journal}

Patient Preference and Adherence is an international, peer-reviewed, open access journal focusing on the growing importance of patient preference and adherence throughout the therapeutic continuum. Patient satisfaction, acceptability, quality of life, compliance, persistence and their role in developing new therapeutic modalities and compounds to

\section{Dovepress}

optimize clinical outcomes for existing disease states are major areas of interest. This journal has been accepted for indexing on PubMed Central. The manuscript management system is completely online and includes a very quick and fair peer-review system. Visit http://www.dovepress.com/ testimonials.php to read real quotes from published authors. 